\title{
Correction of astigmatism with toric intraocular lenses
}

\author{
Ioannis Mallias, Panagiota Mylova, Anastasia Tassiopoulou
}

Laser Plus Eye, Nea Smyrni, Athens, Greece

\begin{abstract}
The purpose of this article is to explain how astigmatism can be eliminated during cataract surgery by using toric intraocular lenses (IOLs). The toric IOL calculation is analysed as well as the various types of toric IOLs. The toric IOL implantation technique is also explained and thoroughly analysed. Moreover, the possibility of residual astigmatism after the surgery is discussed as well as the reasons for this and how to deal with it.
\end{abstract}

KEY WORDS: toric IOLs, astigmatism, cataract surgery

Ophthalmol J 2017; Vol. 2, No. 2, 49-53

\section{ASTIGMATISM AND CATARACT SURGERY}

It is estimated [1] that approximately 19-22.2\% of the population have levels of corneal astigmatism greater than $1.50 \mathrm{D}$ and $1.7-2.7 \%$ have corneal astigmatism greater than $3.50 \mathrm{D}[2,3]$. That is the main reason why correcting astigmatism during cataract surgery has gained popularity in recent years. Correcting corneal astigmatism during cataract surgery has many economic, cosmetic, and practical benefits [4] for the patient.

This correction may be achieved during cataract surgery with the use of toric IOLs or with limbal relaxing incisions (LRI). Using IOLs for astigmatism correction offers the advantages of same-day surgery convenience, efficacy, and long-term stability. IOLs are a predictable method for correcting astigmatism and are also of minimal impact to the cornea [5]. Proceeding with toric IOLs also reduces the possibility of foreign body sensation (after LRI), the risk of dry-eye syndrome, and the dangers of corneal perforation due to LRI [6].

Recently, astigmatic corrections can also be performed with Femtosecond Laser-assisted Cataract Surgery (FLACS), but this is a very expensive option, and worldwide only a few surgery centres have a femtosecond laser for cataract surgery.

\section{TORIC IOL IMPLANTATION TECHNIQUE}

Eyes that have corneal astigmatism of at least 1D and the two major meridians are $90^{\circ}$ apart (regular astigmatism) are candidates for toric IOL implantation. To ensure that the astigmatism is regular, corneal topography must be obtained preoperatively.

When implanting a toric IOL it is important to remember that the spherical equivalent of the lens is identical to that of a spherical IOL of the same dioptric power. Biometry is done in the way the surgeon prefers, and a printout is then obtained with the corresponding lens implant (spherical equivalent) dioptric power. To simplify calculations of the IOL's Keratometric cylinder amount and axis, almost every company producing toric IOLs has come up with easy to use websites where the correct model for each occasion is recommended, together with an indication of the correct placement axis. The data that should be entered in the website are as follows: flat $\mathrm{K}$ value, steep $\mathrm{K}$ value and axis, IOL spherical power to achieve the desired refractive error, surgeon's surgically induced astigmatism, and incision location (Fig. 1).

Cataract surgery with implantation of toric IOL is the same as the normal procedure and does not require special training [7]. However, precise posi- 


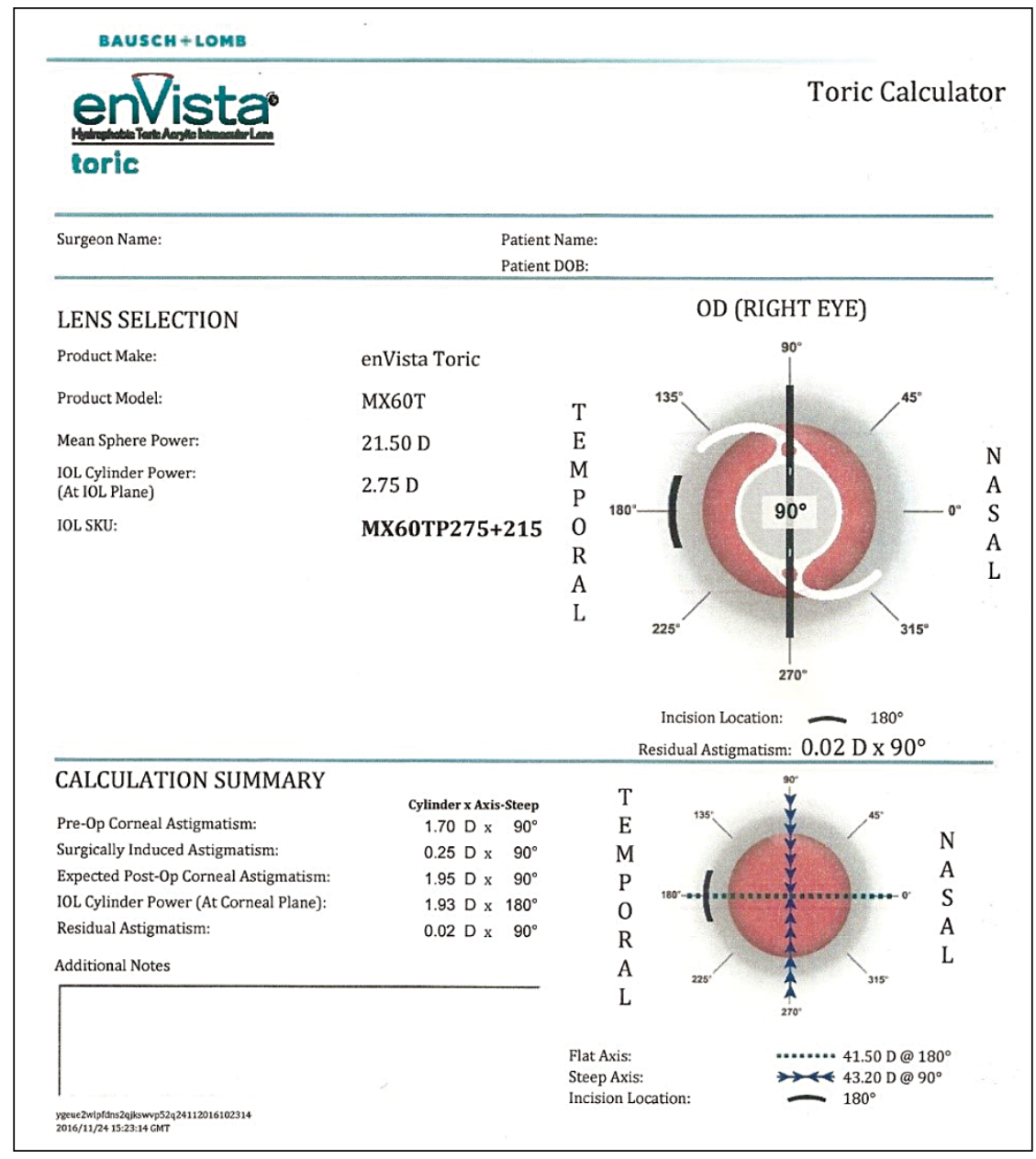

FIGURE 1. Example of toric IOL online calculation

tioning of the IOL is of great importance in order to achieve optimal visual results. Since the toric IOL is aligned relative to the corneal reference marks (Fig. 2), one should take care to ensure that the marks are placed correctly on the cardinal meridians. An accurate way to mark either the horizontal or the vertical axis is to mark the patient while seated at the slit lamp. Also, a variety of reference marking instruments have been designed to help achieving high accuracy with the markings. All these should be used while the patient is seated upright due to the cyclorotation [8] some eyes undergo when changing from the upright to the recumbent position.

Once IOL marks have been done, the phacoemulsification can be performed as usual. Cortical clean-up should be completed and polishing of the anterior and posterior capsules should be performed to minimise capsular bag shrinkage, which can adversely affect the refractive outcome. The IOL is then injected into the capsular bag, which is filled with viscoelastic. Once it is completely

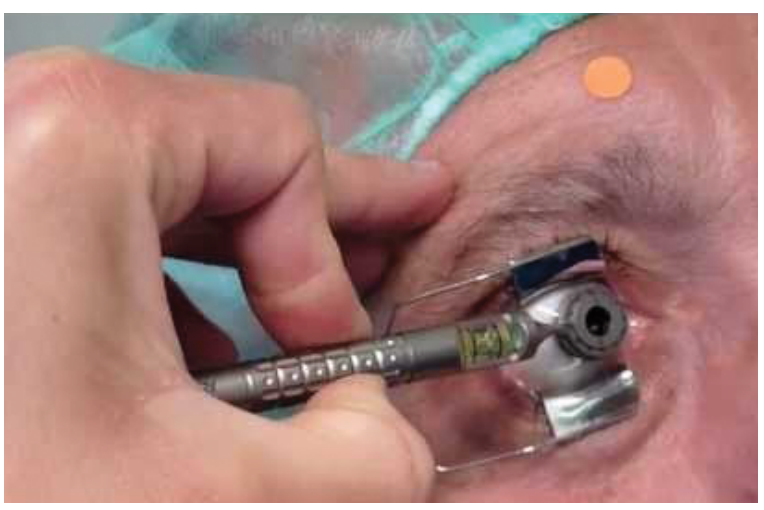

FIGURE 2. Corneal marking

unfolded, the IOL is rotated counter clockwise about $10-15^{\circ}$ short of the intended axis. Cohesive viscoelastic is preferred so that its complete removal may be more readily obtained. Viscoelastic is first removed from behind the IOL and then from the front of the lens and the anterior chamber using Irrigation-Aspiration (IA). Once all the viscoelastic is 


\begin{tabular}{|l|c|c|c|c|}
\hline \multicolumn{2}{|l|}{ Table 1. IOL rotational misalignment effects } \\
\hline IOL rotational misalignment & $10^{\circ}$ & $20^{\circ}$ & $30^{\circ}$ & $>\mathbf{3 0}^{\circ}$ \\
\hline Loss of astigmatism correction effect & $33 \%$ & $66 \%$ & $100 \%$ (but $90^{\circ}$ axis change) & Adds astigmatism \\
\hline
\end{tabular}

cleared, the IOL is rotated so that the last $10-15^{\circ}$ is on axis (clockwise). The final alignment should be made with the eye straight on and coaxial with the microscope, in order to avoid parallax errors. One can avoid these errors by ensuring that the corneal reflex from the microscope light and the Purkinje reflexes off the IOL are aligned, and the IOL plane is perpendicular to the axis of light travel. Once the lens is in the correct alignment, the capsular bag is left slightly under-inflated to allow it to mould to the posterior surface of the IOL to prevent from inadvertent further rotation. Rotational misalignment of the IOL has a detrimental effect on the astigmatism correction (as seen in Tab. 1), so care must be taken to prevent it.

\section{IOL HAPTIC TYPES}

Consideration of IOL haptic design is very important when trying to prevent postoperative lens rotational misalignment. The smaller the IOL compared to the size of the capsular bag, the less contact they have with each other, which results in reduced friction and more risk of rotation [9]. If the IOL is too large compared to the capsular bag, stretching and distortion of the capsular bag may occur [10]. There are several types of toric IOL haptics:

- Plate haptic toric IOLs: Plate haptic IOLs (Fig. 3) demonstrate excellent long-term stability $[11,12]$. They can be rotated both clockwise and anticlockwise within the capsular bag, which assists in lens positioning. Compared to the open-loop haptics, plate haptic IOLs are not so susceptible to the effects of compression from the capsular bag [11]. Plate haptics present with positioning holes that assist the surgeon in aligning the IOL properly. IOLs with plate haptics are: STAAR toric 4203TF (STAAR Surgical Company, CA, USA), Lentis Tplus LU 313-T (Occulentis, Berlin, Germany), and C.AT TORBI 709M (Carl Zeiss Meditec);

- Open-loop haptic toric IOLs: Open-loop haptic lenses (Figs. 4 and 5) appear with excellent early rotational stability compared to plate haptics. The haptic is forced to rotate clockwise, providing sufficient friction. If insufficient fric-

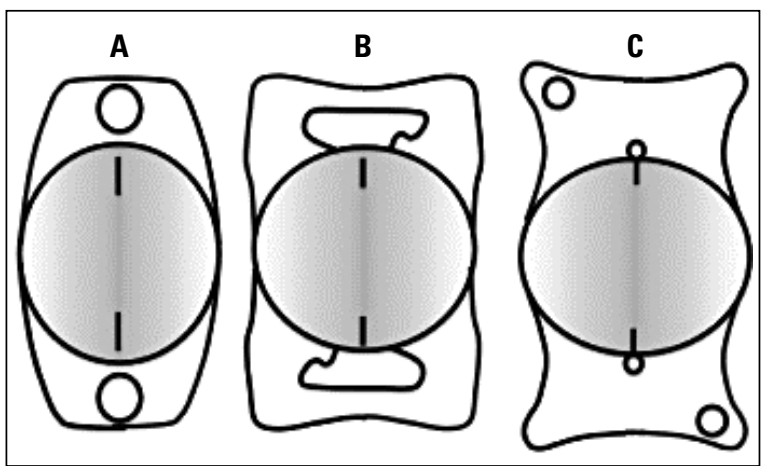

FIGURE 3. Plate haptic toric IOLs. A. STAAR toric 4203TF; B. Lentis Tplus LU 313-T; C. C.AT TORBI 709M

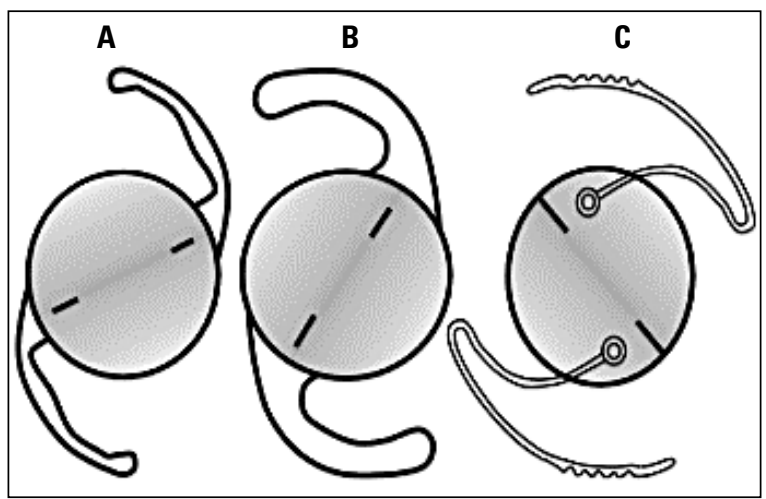

FIGURE 4. Open-loop haptic toric IOLs. A. AcrySof SN60T; B. Lentis Tplus LU312-T; C. Torica-S

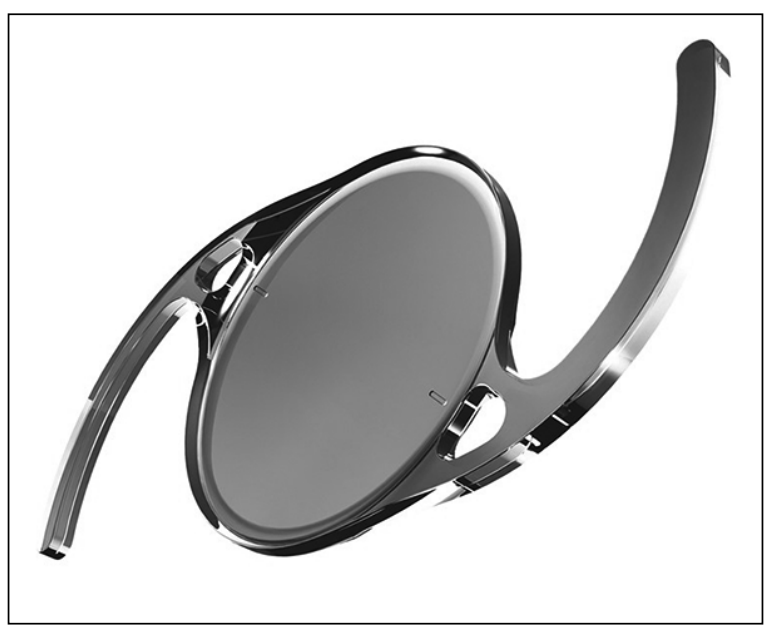

FIGURE 5. Envista Toric IOL 
tion is present, the open loop haptics slip against the capsular bag anti-clockwise $[11,13]$. Open loop haptics can be rotated clockwise only inside the capsular bag. It is recommended that this kind of lens should be first positioned $10^{\circ}$ anticlockwise, and the final position should be established when the viscoelastic has been removed [14]. IOLs with open loop haptics are: AcrySof SN60T (Alcon, Lentis Tplus LU312-T (Occulentis, Berlin, Germany), Torica-S (Human Optics, Erlangen, Germany), and Envista Toric (Bausch \& Lomb, Rochester, USA);

- Closed-loop haptic IOLs: Closed-loop haptics (Fig. 6) are longer than plate haptics, a fact that should give good initial friction. They have a second insertion on the IOL that may resist cap-

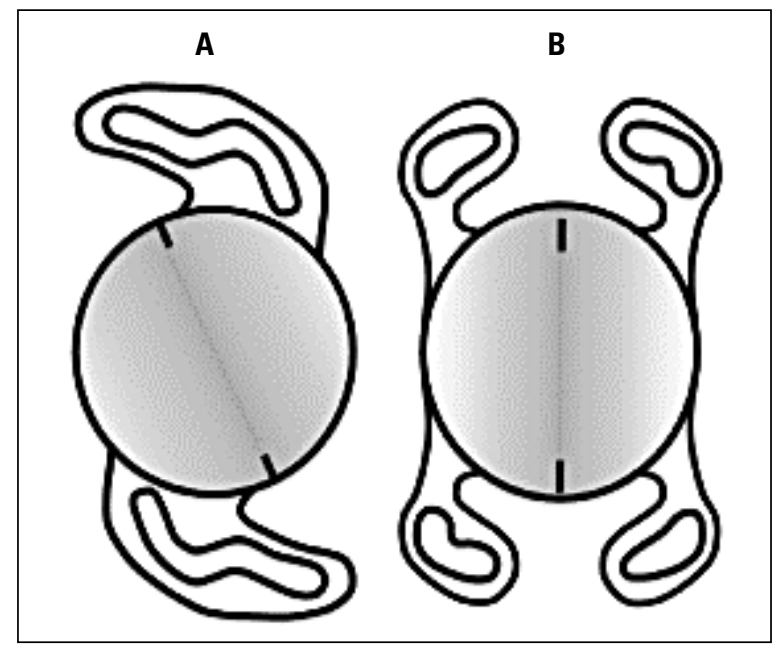

FIGURE 6. Closed-loop haptic toric IOLs. A. T-flex 573T \& 623T; B. Akreos toric IOL sular compression. Results with these lenses are promising [15], and more research is required to prove their effectiveness. Closed-loop haptic IOLs include: T-flex 573T \& 623T (Rayner, Hove, UK) and Akreos toric IOL (Bausch \& Lomb, Rochester, USA).

A thorough table depicting the range of spherical and cylindrical powers and corneal astigmatism capable of correcting for the toric IOLs on the market follows (Tab. 2).

\section{FACTORS THAT CAN CAUSE IOL ROTATION — DEALING WITH RESIDUAL ASTIGMIATISIM}

There are two main surgical factors that can lead to IOL rotation. Following the surgery the Intraocular Pressure (IOP) fluctuates and in some patients the IOP drops to below $5 \mathrm{~mm} \mathrm{Hg}$ [16]. Hypotony has been shown to increase the risk of rotation as the anterior chamber destabilises [17]. Another factor that can cause IOL rotation is the viscoelastic that can remain inside the eye. Care has to be taken to ensure that the viscoelastic is removed from both in front and behind the lens because the viscosity of the substance increases the risk of rotation. The IOL's final position should be dialled in once all of the viscoelastic has been removed.

If residual astigmatism is present following toric IOL implantation, it can be left alone if it is not visually significant. If the magnitude of astigmatism is greater than anticipated, an assessment of the amount of IOL rotation should be made. If a rotational misalignment has occurred, which has required surgical correction, it is better to wait

Table 2. Range of spherical and cylindrical powers and corneal astigmatism capable of correcting for the toric IOLs on the market

\begin{tabular}{|l|c|c|c|c|}
\hline Company & IOL & $\begin{array}{c}\text { Range of spherical } \\
\text { IOL power [D] }\end{array}$ & $\begin{array}{c}\text { Range of cylindrical } \\
\text { IOL power [D] }\end{array}$ & $\begin{array}{c}\text { Range of corneal astigmatism } \\
\text { to be corrected [D] }\end{array}$ \\
\hline Alcon & $\begin{array}{c}\text { Acrisof Toric } \\
\text { SN60T3/T4/T5/T6/T7/T8 }\end{array}$ & +10.0 to $+30.0(0.5)$ & 6.0 to $11.5(1.0)$ & 1.0 to 4.2 \\
\hline Bausch \& Lomb & Envista Toric MX60T & +6.0 to $+30.0(0.5)$ & 1.25 to $5.75(0.5)$ & 0.9 to 4.0 \\
\hline STAAR & AA4203TF & +24.0 to $+28.5(0.5)$ & 2 and 3.5 & 1.4 and 2.4 \\
\hline Human Optics & AA4203TL & +9.5 to $+23.5(0.5)$ & 2 and 3.5 & 1.4 and 2.4 \\
\hline Rayner & Torica-S & -3.0 to $+14.0(1.0)$ & 2.0 to $12.0(0.5)$ & 1.4 to 8.4 \\
\hline Zeiss & $\begin{array}{l}+15.0 \text { to }+25.0(0.5) \\
+26.0 \text { to }+31.0(1.0)\end{array}$ & & \\
\hline & T-flex 573T/623T & +6.0 to $+26.0(0.5)$ & 1.0 to $6.0(1.0)$ & 0.7 to 4.2 \\
\hline & Acri. Comfort643TLC & -10.0 to $+35.0(0.5)$ & 1.0 to $11.0(0.25)$ & 0.7 to 7.7 \\
\hline
\end{tabular}


for a week before performing the correction. For repositioning surgery, reference markers are again necessary for accurate alignment. If fusion between the bag and the IOL is complete, repositioning may not be possible. The remaining astigmatism can be corrected with glasses, excimer laser, or by implantation of a second toric IOL in the sulcus [18].

\section{CONCLUSIONS}

Concluding, toric IOLs are a very good option for astigmatism correction during cataract surgery. The surgical technique is slightly more demanding than the simple phaco procedure, but with practice, the results can be excellent and can provide patient satisfaction.

\section{REFERENCES}

1. Hoffer KJ. Biometry of 7,500 cataractous eyes. Am J Ophthalmol. 1980; 90(3): 360-368, indexed in Pubmed: 7425052.

2. Ninn-Pedersen K, Stenevi U, Ehinger B. Cataract patients in a defined Swedish population 1986-1990. II. Preoperative observations. Acta Ophthalmol (Copenh). 1994; 72(1): 10-15, indexed in Pubmed: 8017180.

3. Ferrer-Blasco T, Montés-Micó R, Peixoto-de-Matos SC, et al. Prevalence of corneal astigmatism before cataract surgery. $\mathrm{J}$ Cataract Refract Surg. 2009; 35(1): 70-75, doi: 10.1016/.j.jcrs.2008.09.027, indexed in Pubmed: 19101427.

4. Laurendeau C, Lafuma A, Berdeaux G. Modelling lifetime cost consequences of toric compared with standard IOLs in cataract surgery of astigmatic patients in four European countries. J Med Econ. 2009; 12(3): 230-237, doi: 10.3111/13696990903257439, indexed in Pubmed: 19728838.

5. Buckhurst PJ, Wolffsohn JS, Davies LN, et al. Surgical correction of astigmatism during cataract surgery. Clin Exp Optom. 2010; 93(6): 409-418, doi: 10.1111/j.1444-0938.2010.00515.x, indexed in Pubmed: 20735787.
6. Khang C. Correction of astigmatism with toric $10 \mathrm{~L}$ implants-practical aspects. Phacoemulsification. 2011: 278-283.

7. Amesbury EC, Miller KM. Correction of astigmatism at the time of cataract surgery. Curr Opin Ophthalmol. 2009; 20(1): 19-24, doi: 10.1097/ ICU.0b013e328319c27a, indexed in Pubmed: 19077825.

8. Smith EM, Talamo JH, Assil KK, et al. Comparison of astigmatic axis in the seated and supine positions. J Refract Corneal Surg. 1994; 10(6): 615-620, indexed in Pubmed: 7719530.

9. Chang DF. Early rotational stability of the longer Staar toric intraocular lens: fifty consecutive cases. J Cataract Refract Surg. 2003; 29(5): 935-940, indexed in Pubmed: 12781279.

10. Lim SJ, Kang SJ, Kim HB, et al. Ideal size of an intraocular lens for capsular bag fixation. J Cataract Refract Surg. 1998; 24(3): 397-402, indexed in Pubmed: 9559478.

11. Patel CK, Ormonde S, Rosen PH, et al. Postoperative intraocular lens rotation: a randomized comparison of plate and loop haptic implants. Ophthalmology. 1999; 106(11): 2190-5; discussion 2196, doi: 10.1016/S0161-6420(99)90504-3, indexed in Pubmed: 10571358.

12. Jampaulo M, Olson MD, Miller KM. Long-term Staar toric intraocular lens rotational stability. Am J Ophthalmol. 2008; 146(4): 550-553, doi: 10.1016/j.ajo.2008.05.040, indexed in Pubmed: 18657795.

13. Pärssinen 0 , Räty J, Vainikainen $J$, et al. Compression forces of haptics of freely rotating posterior chamber intraocular lenses. J Cataract Refract Surg. 1998; 24(3): 415-425, indexed in Pubmed: 9559481.

14. Hyon JY, Yeo HE. Rotational stability of a single-piece hydrophobic acrylic intraocular lens during removal of ophthalmic viscosurgical devices. Am J Ophthalmol. 2010; 149(2): 253-257.e1, doi: 10.1016/j. ajo.2009.08.014, indexed in Pubmed: 19896633.

15. Buckhurst PJ, Wolffsohn JS, Naroo SA, et al. Rotational and centration stability of the Aspheric Akreos AO intraocular lens. J Cataract Refract Surg. 2010; 36(9): 1523-1528.

16. Shingleton $B J$, Rosenberg RB, Teixeira R, et al. Evaluation of intraocular pressure in the immediate postoperative period after phacoemulsification. J Cataract Refract Surg. 2007; 33(11): 1953-1957, doi: 10.1016/j. jcrs.2007.06.039, indexed in Pubmed: 17964404.

17. Pereira FAS, Milverton EJ, Coroneo MT. Miyake-Apple study of the rotational stability of the Acrysof Toric intraocular lens after experimental eye trauma. Eye (Lond). 2010; 24(2): 376-378, doi: 10.1038/ eye.2009.150, indexed in Pubmed: 19557024.

18. Jin H, Limberger IJ, Borkenstein AFM, et al. Pseudophakic eye with obliquely crossed piggyback toric intraocular lenses. J Cataract Refract Surg. 2010; 36(3): 497-502, doi: 10.1016/j.jcrs.2009.07.054, indexed in Pubmed: 20202552. 